\title{
Rhizobacterial community structure in grafted tomato plants infected by Ralstonia solanacearum
}

\author{
LISA NAVITASARI ${ }^{1,2, \bullet}$, TRI JOKO ${ }^{1}$, RUDI HARI MURTI ${ }^{3}$, TRIWIDODO ARWIYANTO ${ }^{1, \bullet \bullet}$ \\ ${ }^{1}$ Department of Plant Protection, Faculty of Agriculture, Universitas Gadjah Mada. Jl. Flora 1, Bulaksumur, Sleman55281, Yogyakarta, Indonesia. \\ Tel./fax.: +62-274-563062, •vemail: triwid@ugm.ac.id \\ ${ }^{2}$ Politeknik Pembangunan Pertanian Malang, Ministry of Agriculture, Malang, Indonesia. Jl. Dr. Cipto No.144a, Sengkkrajan, Malang 65215, East Java, \\ Indonesia. Tel.: +62-341-427771, `email: lissa.nav@yahoo.com \\ ${ }^{3}$ Departement of Agronomy, Faculty of Agriculture, Universitas Gadjah Mada. Jl. Flora 1, Bulaksumur, Sleman55281, Yogyakarta, Indonesia
}

Manuscript received: 28 March 2020. Revision accepted: 28 September 2020.

\begin{abstract}
Navitasari L, Joko T, Murti RH, Arwiyanto T. 2020. Rhizobacterial community structure in grafted tomato plants infected by Ralstonia solanacearum. Biodiversitas 21: 4888-4895. Bacterial wilt disease caused by Ralstonia solanacearum is a devastating soilborne vascular disease of tomato leading to a $100 \%$ yield loss. One of the alternatives to suppress the infestation of $R$. solanacearum infestation is the application of grafting techniques, which has been studied and successfully practiced by tomato growers. However, the infestation mode of $R$. solanacearum and the rhizobacterial community structure in grafted tomato plants are poorly reported. In this study, the rhizobacterial community structure in grafted tomato plants infected by $R$. solanacearum was investigated. The experiment was conducted on tomato germplasms with the implementation of tube grafting using resistant rootstocks (Amelia from Indonesia, H.7996 from Asian Vegetable Research Development Center/AVRDC) and susceptible scion (Servo from Indonesia). The rhizobacterial community structure was analyzed by metagenomic study under 16S rRNA genes sequencing with a distinct region (16SV3-V4) that was amplified using a specific primer (16SV4: 515F-806R) 5'-GTGCCAGCMGCCGCGGTAA and 5'GGACTACHVHHHTWTCTAAT. The results indicated that the grafted tomato plants and resistant rootstocks that were infected by $R$. solanacearum showed significantly lower intensity of bacterial wilt disease compared to the susceptible scion. The rhizobacterial community structure in the grafted tomato plants infected by $R$. solanacearum was indicated by predominant phyla of Proteobacteria, Firmicutes, and Actinobacteria with dominant genera of Pseudomonas and Bacillus. Besides, significant difference was also indicated by species of Geitlerinema sp. in the grafted tomatoes infected by $R$. solanacearum.
\end{abstract}

Keywords: Bacterial wilt, disease intensity, grafting, predominant rhizobacteria

\section{INTRODUCTION}

Bacterial wilt disease caused by Ralstonia solanacearum is a devastating soil-borne vascular disease that severely affects tomato (Solanum lycopersicum L.), leading to a $100 \%$ yield loss (Genova et al. 2013; Hemelda et al. 2019). R. solanacearum infected tomato plants by colonizing the plant rhizosphere, where the pathogen must compete with the other bacterial taxa (Hibbing et al. 2010). After reaching a threshold density, pathogen switches on its virulence gene expression and invades plant roots (Schell $2000)$. Once within xylem vessels, $R$. solanacearum rapidly spreads to aerial plant parts throughout the vascular system (Dalsing et al. 2015) and blocks the water flow via excessive production of extracellular polysaccharides (Genin and Denny 2012). Control strategies of bacterial wilt disease caused by $R$. solanacearum is difficult to perform due to the high variability capacity of the pathogen to survive in diverse environments as well as its wide host range (Yanti et al. 2017). One of the alternatives to suppress the development of bacterial wilt disease is grafting method using rootstock from resistant varieties.

Grafting has been utilized to manage bacterial wilt disease in tomato plants worldwide (Rivard et al. 2012). The method can provide an effective management strategy to reduce bacterial wilt disease incidence and subsequent crop loss (Louws et al. 2010). Grafting method using rootstock from resistant varieties is the most effective method in disease control of bacterial wilt disease in the fields. The grafting method using resistant rootstock significantly reduces bacterial wilt incidence in tomato plants (Louws et al. 2010; McAvoy et al. 2012). Resistant rootstock in grafting also influences and changes microbial community in the rhizosphere (Gilardi et al. 2013; PerezAlfoceae et al. 2015), thereby changing the rhizobacterial diversity and affecting the pathogens in the rhizosphere. Poudel et al. (2019) reported that grafting between tomato BHN589 and Maxifort or RST-04-106 without infection of $R$. solanacearum indicated that the diversity and abundance bacterial communities in rhizosphere were higher than in endosphere, and the abundance of bacteria in the grafted tomato plants was higher than in the non-grafted ones. However, there is little information about how the infection of $R$. solanacearum in grafted tomato plants suppresses bacterial wilt disease and influences the diversity of rhizobacterial community structure. Therefore, the effects of tomato grafting using resistant rootstock on the rhizobacterial community structure and bacterial wilt disease intensity were investigated in this study. The evidence that the rhizobacterial community structure was influenced by resistant rootstock, grafting, and infections of $R$. solanacearum were provided. 


\section{MATERIALS AND METHODS}

\section{Preparation of bacterial inoculum}

Ralstonia solanacearum was isolated from the rhizosphere of tomato plants showing bacterial wilt disease symptoms in Yogyakarta, Indonesia. The phylotype, race, and biovar of isolated $R$. solanacearum were also analyzed. $R$. solanacearum was incubated at a temperature of $28^{\circ} \mathrm{C}$ and grown on Yeast Peptone Glucose agar (Yeast extract 5 $\mathrm{g} / \mathrm{L}$, peptone $10 \mathrm{~g} / \mathrm{L}$. Glucose $20 \mathrm{~g} / \mathrm{L}$, agar $15 \mathrm{~g} / \mathrm{L}$, and aquadest 1 L) (Laeshita and Arwiyanto 2007). $R$. solanacearum grown on YPGA medium for 48 hours were added to $10 \mathrm{ml}$ sterile aquadest and then shaken, and the suspension of $R$. solanacearum was measured with Spectrophotometer (UV-vis Genesys 10S, Thermo Scientific) to obtain the OD 0.1 at $\lambda 580 \mathrm{~nm}$. The suspension of $R$. solanacearum having OD 0.1 was used for the infection treatment in the grafted tomato plants.

\section{Grafting and planting in the field}

The rootstocks from two resistant tomato cultivars were used for grafting. The resistant rootstocks used were Amelia (Matahari Seed Company) and H7996 (Asian vegetable research development Center/AVRDC), while the susceptible scion used was Servo (East-West Company). The grafting made were GrftAmlS (Amelia and Servo) and GrH7996S (H7996 and Servo) using tube graft method. The grafts were held in plastic tubes with a diameter of $1 \mathrm{~cm}$, and grafting performed when rootstock and scion have same diameter $(1 \mathrm{~cm})$ (21 days old). The grafts were then moved into a healing chamber and maintained for ten days at a temperature of $22-25^{\circ} \mathrm{C}$ and relative humidity of $90-95 \%$. After 10 days in healing chamber, the rooted grafted and non-grafted tomato plants (control plants) were removed and then planted in field under plastic mulch (Arwiyanto et al. 2015). A $30 \mathrm{ml}$ of $R$. solanacearum inoculum was splashed close to the roots of plants and the bacterial wilt disease intensity was measured every week by calculating the disease intensity (Widyaningsih et al. 2019; Solekha et al. 2019). The experiment was arranged in a randomized complete block design consisting of 5 treatments and 4 replications with 10 plants within each treatment, and the total number of experimental units was 200 plants (Arwiyanto et al. 2018).

$$
\mathrm{I}=\frac{\Sigma(\mathrm{nXv})}{\mathrm{NXZ}} \times 100 \%
$$

\section{Where:}

I : Disease intensity (\%)

$\mathrm{v}:$ : number of damaged plants

$\mathrm{v}$ : Score of the damage level (1: healthy; score 3:< $15 \%$ wilt on leaf; score 5: $3>15 \%-45 \%$ wilt on leaf; score 7: $>45 \%-85 \%$ wilt on leaf; and Score 9: $>85 \%$ wilt on leaf and death)

$\mathrm{Z}$ : the highest damage level value

$\mathrm{N}$ : Total sample plants observed

\section{Preparation of rhizosphere soil samples for metagenomic analysis}

Sample analysis of rhizobacteria taken from grafted (GrftAmlS and GrH7996S) and non-grafted tomato plants (Amelia, H7996, Servo) infected by $R$. solanacearum was performed at 30 days after planting. Total samples for analysis were 15 samples of $50 \mathrm{~g}$ of rhizosphere soil. The rhizosphere soil was collected as previously described (Riley and Barber, 1969).

\section{Extraction of genomic DNA and Amplicon Generation}

Total genomic DNA from each sample was extracted using Phusion ${ }^{\circledR}$ High-Fidelity PCR Master Mix (New England Biolabs). The DNA concentration and purity were monitored on $1 \%$ agarose gels. According to the concentration, DNA was diluted to $1 \mathrm{ng} / \mu \mathrm{L}$ using sterile water. Meanwhile, the amplicon generation, 16S rRNA (genes of distinct regions/16SV3-V4), was amplified using specific primer (16SV4: 515F-806R) 5'GTGCCAGCMGCCGCGGTAA and 5'GGACTACHVHHHTWTCTAAT. Samples with a bright main strip between 400-450bp were chosen for further experiments. Then, the libraries generated with Ion $^{+}$ Fragment Library Kit 48 rxns for Thermo fisher and quantified via Qubit and Q-PCR were sequenced by IonS5 ${ }^{\mathrm{TM}} \mathrm{XL}$ (Thermo fisher) (Wang et al. 2018).

\section{Metagenomic analysis}

Metagenomic analysis was performed at Novogene Bioinformatics Technology Co., Ltd (Singapore). A $5 \mu \mathrm{g}$ DNA was used to construct 400-450bp sequencing libraries performed by Illumina Hiseq PE150 (Illumina, San Diego, USA). The libraries generated with Ion Plus Fragment Library Kit 48 rxns for Thermofisher and quantified via Qubit and Q-PCR were sequenced by IonS5 ${ }^{\mathrm{TM}} \mathrm{XL}$ (Thermofisher). Single-end read was assigned to samples based on their unique barcode and truncated by cutting off the barcode and primer sequence. The reads were compared with the reference database (Gold database, http: //drive5.com/uchime/uchime_download.html) using UCHIME algorithm (UCHIME Algorithm, http: //www.drive5.com/usearch/manual/uchime_algo.html) to detect chimera sequences (report template life.pl), and then the chimera sequences were removed to get effective reads final (Caporaso et al. 2010, Edgar et al. 2011). Sequences analyses were performed with Uparse software (Uparse v7.0.1001 http: //drive5.com/uparse/) using all the effective reads. Sequences with $\geq 97 \%$ similarity were assigned to the same OTUs (Haas et al. 2011). Analysis using Mothur software was performed on the SSUrRNA database of SILVA Database (http: //www.arb-silva.de/) used for species annotation at each taxonomic rank (Threshold: 0.8 1) kingdom, phylum, class, order, family, genus, and species. Meanwhile, the phylogenetic relationship of all OTUs representative sequences was analyzed using the MUSCLE (Version 3.8.31, http: //www.drive5.com/muscle/) (Quast et al. 2012). Analysis of diversities and species in each sample was carried out based on all effective reads by $97 \%$ DNA sequence with operational Taxonomy Units (OTUs) generating 97\% 
sequence identity homologous in species, and then the rank of relative abundance and diversities of rhizobacteria were drawn by Ternary Plot.

\section{Statistical analysis}

The data of bacterial wilt disease intensity were statistically analyzed with ANOVA, and the data showing significant differences were further analyzed with Duncan Multiple Range Test (DMRT) at alpha 5\%. Meanwhile, the rhizobacterial community structure in within-group and among groups was determined using T-test, and the variation of rhizobacteria species in groups was analyzed with Metastats.

\section{RESULTS AND DISCUSSION}

\section{Analysis of Ralstonia solanacearum and measurement of bacterial wilt disease intensity}

Ralstonia solanacearum observed in this study belongs to phylotype 1 , race 1 , and biovar 3 . There was no significant difference in the bacterial wilt disease intensity between the grafted tomato plants and resistant rootstocks (Amelia and H7996). On the contrary, significant difference in the bacterial wilt disease intensity was observed in the susceptible scion (Servo) (Table 1). Generally, bacterial wilt disease intensity in the grafted tomato plants, resistant rootstocks, and susceptible scion increased from 7 to 28 days after transplanting (Figure 1). The increase of bacterial wilt diseases intensity is related to the resistance level of the rootstock, susceptible scion, and the combination (grafting) (Table 1). The intensity of bacterial wilt disease in the grafted tomato plants (GrftAmlS and GrH7996S) was lower compared to that in the susceptible scion (Servo), but higher than that in the resistant rootstocks (Amelia and H.7996) (Figure 1). The intensity of bacterial wilt disease in the resistant rootstocks (Amelia and H.7996) and grafted tomato plants (GrftAmlS and GrH7996S) was significantly lower than that in the susceptible scion (Servo) (Table 1).

Table 1. Bacterial wilt disease intensity and resistance level

\begin{tabular}{lcl}
\hline Group & $\begin{array}{c}\text { Bacterial wilt } \\
\text { disease intensity } \\
(\boldsymbol{\%})\end{array}$ & \multicolumn{1}{c}{ Resistance level } \\
\hline Amelia & $21.8750 \mathrm{a}$ & Moderate resistant \\
GrftAMlS & $38.0000 \mathrm{a}$ & Moderately susceptible \\
H.7996 & $30.3750 \mathrm{a}$ & Moderately resistant \\
GrH.7996S & $40.6875 \mathrm{a}$ & Moderately susceptible \\
Servo & $69.3750 \mathrm{~b}$ & Susceptible \\
\hline
\end{tabular}

Note: Means followed by the same letters are not significantly different based on the Duncan's Multiple Range Test (DMRT) $(\mathrm{p} \leq 0.05)$. Resistant level based on Janaki and Putturaja (2012). GrftAMIS (grafting Amelia and Servo), GrH7996S (Grafting H7996 and Servo)
Grafting and the infection of $R$. solanacearum in tomato plants influenced the diversity of rhizobacterial community. Within the rhizobacterial community, the dominant phyla were Proteobacteria $(67.65 \%)$, Firmicutes (16.43\%), and Actinobacteria (15.92\%). The phylum of proteobacteria was indicated by Gammaproteobacteria, Alphaproteobacteria, and Betaproteobacteria. The Gammaproteobacteria were Pseudomonadales and Xanthomonadales, indicated by Pseudomonas resinovorans and Lysobacter sp., respectively. The alphaproteobacteria were predominated by Sphingomonadales (Sphingomonas jaspsi), and Betaproteobacteria (Paucimonas (Burkholderiales) and Methilophylus (Methylopilales)) (Figure 3). Meanwhile, the phylum of Firmicutes and Actinobacteria were predominated by the genus of Bacillus and Nocardiodes, respectively, with dominant species of Bacillus funiculus (1.45\%) (genus of Bacillus), Fictibacillus arsenicus (2.31\%) (genus of Fictibacillus), and Nocardiodes marinus $(1.17 \%)$ (genus of Nocardiodes) (Figure 3).

The resistant rootstocks of Amelia and grafting between resistant rootstocks of Amelia and susceptible scions of Servo were indicated by dominant rhizobacterial species of Fictibacillus arsenicus. Meanwhile, the resistant rootstocks of $\mathrm{H} 7996$ were indicated by predominant rhizobacterial species of Pseudomonas resinovorans. The different result was found in the grafting between resistant rootstocks of H7996 and susceptible scions of Servo that showed similar dominant rhizobacterial species (Sphingomonas jaspsi) to the dominant rhizobacterial species in the susceptible scion (Figure 5). Besides, the relative abundance of $R$. solanacearum was also found in the rhizosphere. The resistant rootstocks of Amelia and the grafting between resistant rootstocks of Amelia and susceptible scion showed relative abundance of $R$. solanacearum that was higher compared to the relative abundance in the resistant rootstocks of H.7996, the grafting between resistant rootstocks of H.7996 and susceptible scion, and the susceptible scion. The relative abundance of $R$. solanacearum in the grafted tomato plants was higher than in the resistant rootstocks but smaller than in the susceptible scion (Figure 5).

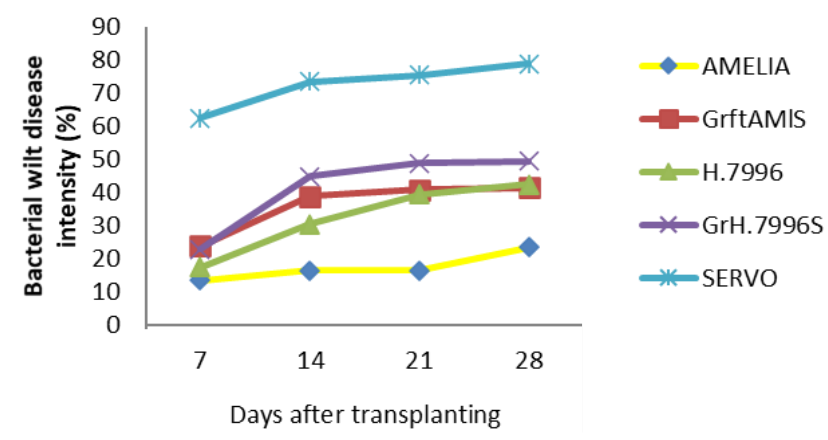

Figure 1. Percentage of bacterial wilt disease intensity in resistant rootstocks (Amelia and H.7996), susceptible scion (Servo), and grafted tomato plants using resistant rootstock and susceptible scion 
The relative abundance of $R$. solanacearum in rhizosphere affected the relative abundance of others rhizobacteria as shown in Table 2 that indicated the relative abundance of $R$. solanacearum affected the difference of rhizobacteria in phylum, class, order, and species. Significant difference in rhizobacterial phylum was shown by Phylum Latescibacteria. The phylum Latescibacteria was significantly different in GrftAmlS, GrH7996S, resistant rootstocks of $\mathrm{H} 7996$, and susceptible scion of
Servo but not in the resistant rootstocks of Amelia. The significant differences in class and order of rhizobacteria were shown by class of unidentified Acidobacteria of the phylum Acidobacteria and order of unidentified Alphaproteobacteria and Acidobacteriales. The relative abundance of $R$. solanacearum in rhizosphere also influenced significant difference of rhizobacteria in species of Geiternema sp. in the grafted tomato plants (GrftAmlS and GrH7996S) and susceptible scion of servo.
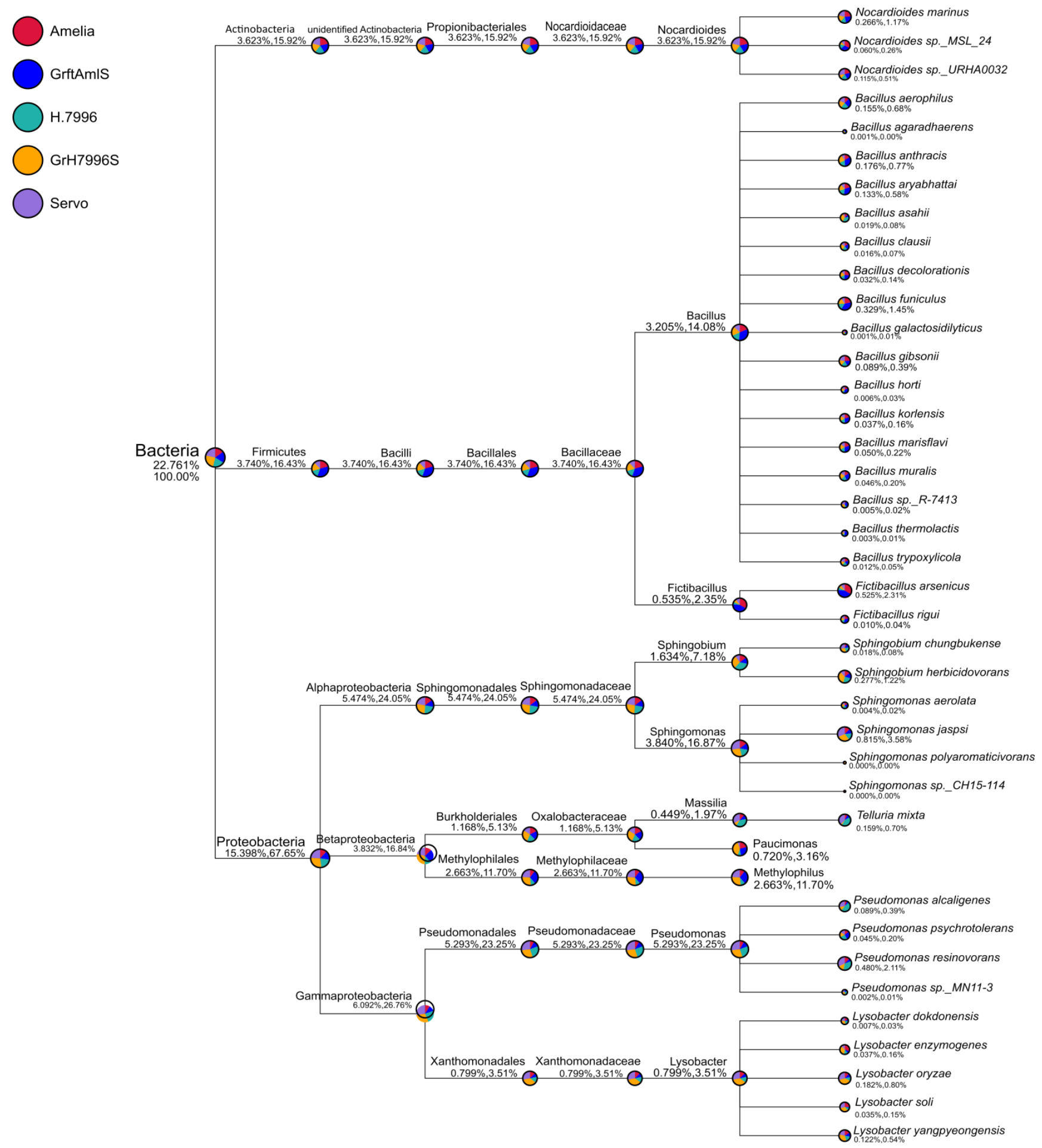

Figure 3. Diversity of rhizobacterial community structure 


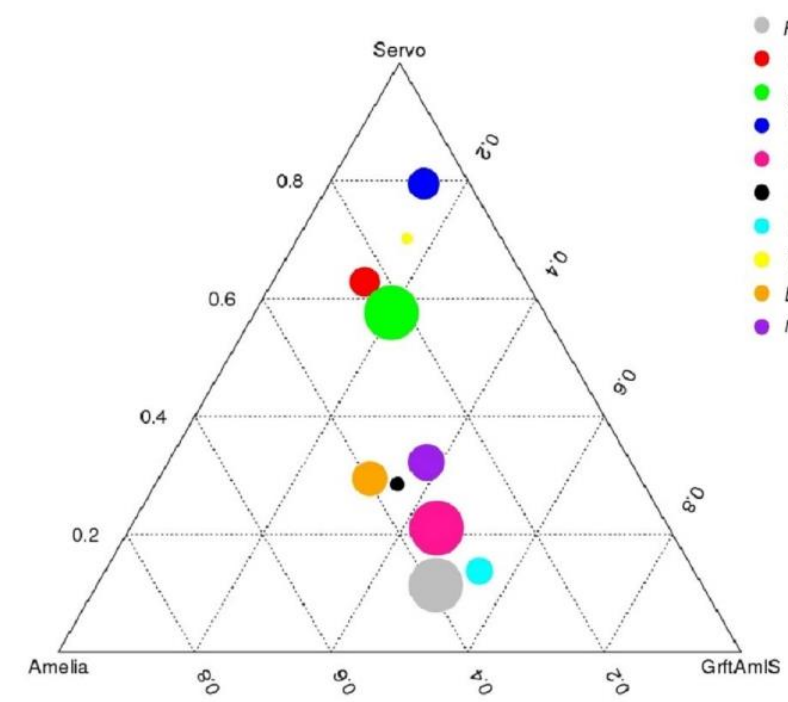

Fictibacillus arsenicus

- Pseudomonas resinovorans

- Sphingamonas jaspsi

- Thermomonas haemolytica

- Ra/stonia solanacearum

- Sphingobium herbicidovorans

Bacillus funicuius

Telluria mixta

Bradyrhizobium elkanij

Nitrospira cf.moscoviensis SBR1015

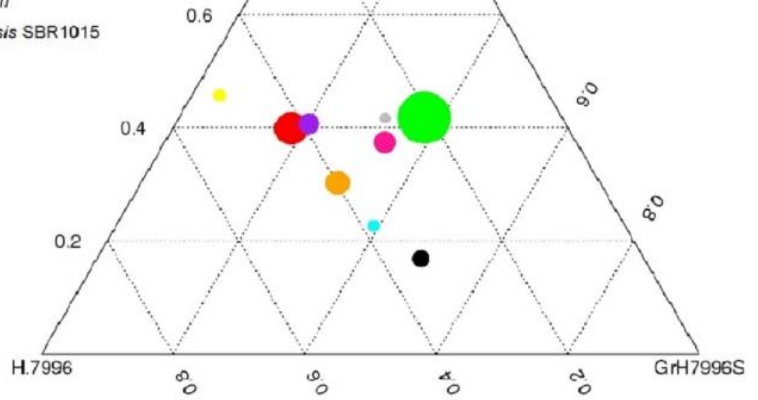

Figure 4. Predominant species of rhizobacteria in resistant rootstocks, susceptible scions, and grafted tomato plants. The resistant rootstocks are Amelia and H.7996; the grafting of Amelia-Servo is GrftAmlS, the grafting of H.7996-Servo is GrH.7996S, and the susceptible scion is Servo

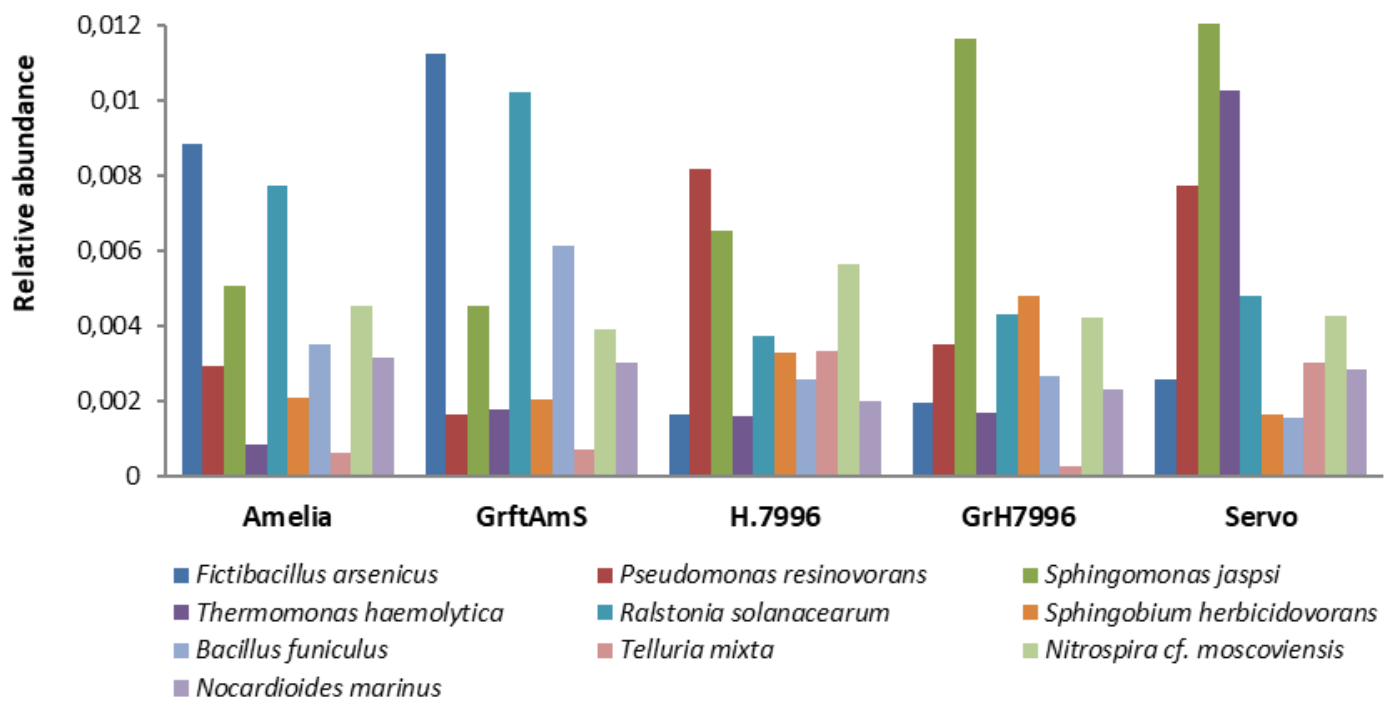

Figure 5. Top ten dominant relative abundant rhizobacterial species

Table 2. The difference in the abundance of the rhizobacteria in grafted tomato plants, resistant rootstocks, and susceptible scions

\begin{tabular}{|c|c|c|c|c|}
\hline \multirow{2}{*}{ Group } & \multirow[b]{2}{*}{ Phylum } & \multicolumn{2}{|c|}{ The difference in the abundance of rhizobacteria between group } & \multirow[b]{2}{*}{ Species } \\
\hline & & Class & Order & \\
\hline Amelia & NS & Unidentified Acidobacteria* & $\begin{array}{l}\text { Acidobacteriales**, } \\
\text { unidentified Alphaproteobacteria* }\end{array}$ & NS \\
\hline GrftAmlS & Latescibacteria $* *$ & Unidentified Acidobacteria* & $\begin{array}{l}\text { Acidobacteriales**, } \\
\text { unidentified Alphaproteobacteria* }\end{array}$ & NS \\
\hline H.7996 & Latescibacteria $* *$ & Unidentified Acidobacteria* & $\begin{array}{l}\text { Acidobacteriales**, } \\
\text { unidentified Alphaproteobacteria* }\end{array}$ & NS \\
\hline GrH7996S & Latescibacteria $* *$ & Unidentified Acidobacteria* & $\begin{array}{l}\text { Acidobacteriales**, } \\
\text { unidentified Alphaproteobacteria* }\end{array}$ & Geitlerinema sp.** \\
\hline Servo & Latescibacteria $* *$ & Unidentified Acidobacteria* & $\begin{array}{l}\text { Acidobacteriales**, } \\
\text { unidentified Alphaproteobacteria* }\end{array}$ & Geitlerinema sp.** \\
\hline
\end{tabular}


The use of resistant cultivar in the management of bacterial wilt disease caused by $R$. solanacearum is one of the highest priorities. For instance, resistant rootstocks in grafting have been used to suppress bacterial wilt disease. Huet (2014) reported that the most effective method of disease control of bacterial wilt disease is through the use of resistant cultivar. McAvoy et al. (2012) also reported that a commonly used grafting method using resistant rootstock significantly decreased bacterial wilt incidence in fields. The result in this study showed that bacterial wilt disease intensity in grafted tomato plants was not significantly different compared to that in the resistant rootstocks, but significantly lower than that in the susceptible scion. It indicates that grafting using resistant rootstocks reduced bacterial wilt diseases intensity caused by $R$. solanacearum in fields. The use of resistant rootstocks in grafting can restrict bacterial spread in the roots. Furthermore, resistant plants can also limit the bacterial spread in the vascular stem tissue. However, combination grafting of resistant rootstocks with susceptible scion changes the resistance level from moderately resistant to moderately susceptible. The resistance level of Amelia and H7996 are moderately resistant, making them recommended as rootstocks that are resistant to $R$. solanacearum (Genova et al. 2013, Laeshita and Arwiyanto, 2017).

The change in resistance level from resistant to moderately resistant is influenced by the new race of $R$. solanacearum and the environment. A new pathogen race destroys the resistance of a plant variety. Plant varieties with vertical resistance (resistance is determined by a single gene or a few genes and only effective against some strains of pathogen) need replacement of resistance every few years $(3,5$, or 10 years), and this is depending on the pathogen genetic plasticity, a particular gene, or a genetic combination, as well as environmental conditions on the development of the disease (Laeshita and Arwiyanto, 2017; Sutrisno et al. 2018). Deberdt et al. (2014) also reported that tomato cultivar H-7996 is known to be resistant to $R$. solanacearum but changing to be susceptible after being inoculated with $R$. solanacearum strains IIB, which is an emerging ecotype. The resistance and susceptibility of plant varieties are influenced by environmental factors, such as changes in the physical environment and pathogens race (Semangun, 2006; Wei et al. 2017). Besides, the change in the resistance level is also influenced by relative abundance of $R$. solanacearum. Generally, all grafted tomato plants, resistant rootstock, and susceptible scion showed relative abundance of $R$. solanacearum in rhizosphere. However, the relative abundance of $R$. solanacearum in resistant rootstock was higher than that in the grafted tomato plants and susceptible scion. It indicates that resistant rootstock can limit bacterial spread in plants, and the effect is indicated by the low intensity of bacterial wilt disease compared to the grafted tomato plants and susceptible scion. However, grafted tomato plants with a combination of resistant rootstock and susceptible scion showed lower intensity of bacterial wilt disease intensity compared to the susceptible scion. It was influenced by relative abundance of $R$. solanacearum in the grafted tomato that was higher than in the resistant rootstock but lower than in the susceptible scion. Besides, the intensity of bacterial wilt disease was also influenced by diversity of rhizobacteria in the rhizosphere. When attacked by pathogen, plant select and recruit bacteria in rhizosphere by root exudates, and then root exudates influence community structure of the rhizosphere microbes by recruiting beneficial microbes and repelling pathogens. The recruitment and selection of rhizobacteria influenced the rhizobacterial community structure (Bakker et al. 2013, Wei et al. 2015).

The rhizobacterial diversity and community structure associated with the relative abundance of R. solanacearum were shown by dominant rhizobacterial phylum of rhizobacteria. The dominant rhizobacterial phylum was shown by phylum Proteobacteria (alpha, beta, and gamma proteobacteria), Firmicutes (Bacilli), and Actinobacteria (Nocardiodes). Mendes et al. (2011) reported that infection of pathogen in plant was influenced by predominant phylum of Proteobacteria, Firmicutes, and Actinobacteria. Proteobacteria (alpha, beta, and gamma proteobacteria) and firmicutes (Bacilli) were identified as the most dynamic taxa associated with disease suppression. Actinobacteria have been observed to exhibit uniquely increased survival rates through periods of environmental stress (Legget et al. 2012). When attacked by pathogen, plants seem to actively select specific elements of their bacterial rhizosphere microflora and then select and recruit specific soil microbes into the rhizosphere microbiome. Plant roots also influence specific functions of the microbiome, and a plant seems to respond to pathogen infection by systemic signaling (Joko et al. 2018), leading to enhanced biocontrol activity in the microbiome (Bakker et al. 2013; Massart et al. 2015). Infection of pathogen in the rhizosphere also affects plant defense and recruitment of beneficial microbe by root exudate. Plant exudation can change the rhizosphere community composition by recruiting certain beneficial microbes and directly repelling the pathogen (Joko et al. 2012).

Infection of $R$. solanacearum pathogen showed significant effect on rhizobacterial phylum. The significant difference in the rhizobacterial phylum related to relative abundance of $R$. solanacearum was shown by phylum Latescibacteria. Latesbacteria has SAGs harbor extensive transport systems for sugars and amino acids/oligopeptides uptake (Youssef et al. 2015). Uronic acids and uronic acid derivatives are potentially imported using a single common transporter, a sugar-phosphate permease transporter of the major facilitator superfamily (Joko et al. 2007) similar to the ExuT transporter of $R$. solanacearum (Gonzalez and Allen 2003). Besides, the significant difference in rhizobacteria was also shown by Geitlerinema sp. Patel et al. (2018) reported that the Cyanobacterium Geitlerinema sp. has the characteristic of phycocyanin that correlated with antioxidant activity and therapeutic agent against oxidative stress. Infection of $R$. solanacearum causes oxidative stress on plant, and this response of plants is used to adapt and suppress pathogen. Colonization of $R$. 
solanacearum is exposed to host-derived ROS, which triggers a bacterial oxidative stress response that adapts the pathogen to the xylem environment (Flores and Allen, 2009). Infection of $R$. solanacearum was also related to the dominant rhizobacterial species in genus Bacillus (Fictibacillus arsenicus and Bacillus funiculus), Pseudomonas (Pseudomonas resinovorans), and Sphingomonas (Sphingomonas jaspsi). The genus of Bacillus and Pseudomonas are known as antagonistic microorganisms, which are mainly isolated to control pathogens from the rhizosphere and plant microflora (Lamsal et al. 2012). P. resinovorans displays a wide range of antimicrobial and antifungal activity (Fikri et al. 2018), and S. jaspsi produces carotenoids, including zeaxanthin. Zeaxanthin is one of the carotenoids that are a stronger ROS scavenger. When bacterial cells are exposed to the oxidative stress as a result of cellular metabolism, zeaxanthin accumulated in the bacterial cell membrane might quench the ROS, thereby decreasing their lethal effects (Tian et al. 2007).

In conclusion, grafting using resistant rootstock and infection of $R$. solanacearum influences the intensity of bacterial wilt disease and rhizobacterial community structure. The intensity of bacterial wilt disease intensity in grafted tomato plants was not significantly different compared to that in the resistant rootstock, but significantly different from that in the susceptible scion. The grafted tomato plants showed lower intensity of bacterial wilt diseases compared to the susceptible scion, but showed higher intensity compared to the resistant rootstocks. The intensity of bacterial wilt diseases is related to the rhizobacterial community structure indicated by dominant phyla in Proteobacteria, Firmicutes, and Actinobacteria with dominant genera of Pseudomonas and Bacillus. Besides, significant difference is also indicated by species of Geitlerinema sp. on tomatoes grafted infected by $R$. solanacearum.

\section{ACKNOWLEDGMENTS}

This article is part of the first author's doctoral program funded by the scholarship from the Ministry of Research and Technology/National Research and Innovation Agency and the Ministry of Agriculture.

\section{REFERENCES}

Arwiyanto T, Nurcahyanti SD, Indradewa D, Widada D. 2015. Grafting of Local Commercial Tomato Varieties with H-7996 and Eg-203 to Suppress Bacterial Wilt (Ralstonia solanacearum) in Indonesia. Acta Horticultura 1069: 173-178.

Arwiyanto T, Triman B, Sulandari S, Suryanti. 2018. Preliminary test of a local tomato cultivar as a rootstock to control two soil-borne plant pathogens. Acta Horticultura 1207: 51-54.

Bakker PHM, Roeland LB, Rogier FD, Paul CAW, Corne MJP. 2013. The Rhizosphere revisited: root microbiomics. Plant Sci 4: 1-7.

Caporaso JG, Kuczynski J, Stombaugh J. 2010. QIIME allows analysis of high-throughput community sequencing data. Nature Methods 7: 335.

Dalsing BL, Alicia NT, Enid T, Annet SM, Caitilyin A. 2015. Ralstonia solanacearum uses inorganic nitrogen metabolism for virulence, ATP production, and detoxification in the oxygen-limited host xylem environment. ASM 6 (2): 1-13.

Deberdt P, Guyot R, Coranson-Beaudu J, Launay M, Noreskal P, Riviere, E. Wicker. 2014. Diversity of Ralstonia solanacearumin French Guiana Expands Knowledge of the "Emerging Ecotype". Phytopathol 104: 586-596.

Edgar RC, Haas BJ, Clemente JC, Quince C, Knight R. 2011. UCHIME improves sensitivity and speed of chimera detection. Bioinformatics 27 (2): 194-200

Fikri ASI, Irman AR, Norefrina S, Ainon H. 2018. Isolation and Identification of local bacteria endophyte and Screening of Its Antimicrobial property against pathogenic bacteria and fungi. AIP Conf Proc 1940 (1): 020072.

Flores-Cruz Z, Allen C. 2009. Ralstonia solanacearum encounters an oxidative environment during tomato infection. Mol Plant Microb Interact 22: 773-782.

Genin S, Denny TP. 2012. Pathogenomics of the Ralstonia solanacearum species complex. Ann Rev Phytopathol 50: 67-89.

Genova C, Schreinemachers P, Sefa VA. 2013. An Impact Assessment of AVRDC's Tomato Grafting in Vietnam. World Vegetable Center, Taiwan.

Gilardi G, Gullino, Garibaldi. 2013. Critical aspects of grafting as a possible strategy to manage soil-borne pathogens. Sci Horticul 149: 19-21.

Gonzales ET, Allen C. 2003. Characterization of a Ralstonia solanacearum operon required for polygalacturonate degradation and uptake of galacturonic acid. Mol Plant Phytopathol Interact 16 (6): 36-44.

Haas BJ, Gevers D, Earl AM. 2011. Chimeric 16S rRNA sequence formation and detection in Sanger and 454-pyrosequenced PCR amplicons. Genome Res 21: 494-504.

Hemelda NM, Safitri R, Suhandono S. 2019. Genetic diversity of Ralstonia solanacearum, a phytopathogenic bacterium infecting horticultural plants in Java, Indonesia. Biodiversitas 20: 364-372.

Hibbing ME, Fuqua C, Parsek MR, Peterson SB.2010. Bacterial competition: surviving and thriving in the microbial jungle. Nat Rev Microbiol 8: 15-25.

Huet G. 2014. Breeding for resistance to Ralstonia solanacearum. Plant Sci 5 (715): 1-5.

Janaki V, Putturaju TB. 2012. Studies on Percent Incidence and Reaction of Tomato Cultivar on Bacterial Wilt. Int J Plant Prot 5: 175-176.

Joko T, Hirata H, Tsuyumu S. 2007. A sugar transporter (MfsX) is also required by Dickeya dadantii 3937 for in planta fitness. Journal of General Plant Pathology 73: 274-280.

Joko T, Koentjoro MP, Somowiyarjo S, Rohman MS, Liana A, Ogawa N. 2012. Response of rhizobacterial communities in watermelon to infection with cucumber green mottle mosaic virus as revealed by cultivation-dependent RISA. Arch Phytopathol Plant Protect 45: 1810-1818.

Joko T, Umehara M, Murata T, Etoh H, Izumori K, Tsuyumu S. 2018. Hyperinduction of pectate lyase in Dickeya chrysanthemi EC16 by plant-derived sugars. J Plant Interact 13: 141-150.

Laeshita P, Arwiyanto T. 2017. Resistance test of several tomato varieties to bacterial wilt diseases caused by Ralstonia solanacearum. Jurnal Perlindungan Tanam Indonesia 21 (1): 51-53.

Lamsal K, Kim SW, Kim YS, Lee YS. 2012. Application of rhizobacteria for plant growth promotion effect and biocontrol of anthracnose caused by Colletotrichum acutatum on pepper. Mycobiology 40: 244251.

Legget MJ, McDonnel G, Denyer SP, Setlow P, Maillard JY. 2012. Bacterial spore structures and their protective role in biocide resistance. J Appl Microbiol 113: 485-498.

Louws FJ, Rivard, Kubota C. 2010. Grafting fruiting vegetables to manage soil-borne pathogen, foliar pathogen, arthropod, and weeds. Sci Hort 127: 127-146.

Massart S, Martinez-Medina M, Jijakli MH. 2015. Biological control in the microbiome era: challenges and opportunities. Biol Control 89 (98): 108 .

McAvoy T, Joshua HF, Steven LR, Stephen MO, Mathews LP. 2012. Evaluation of grafting using hybrid rootstocks for management of bacterial wilt in field tomato production. Hort Sci 47 (5): 621-625.

Mendes R, Menno VDV, Marco K, Johannes HMS. 2011. Deciphering the rhizosphere microbiome for disease-suppressive bacteria. Science 332: 1097-1100. 
Patel HM, Rajesh P, Rastogim Ujjval T, Datta M. 2018. Structural characterization and antioxidant potential of phycocyanin from the cyanobacterium Geitlerinema sp. H8DM. Alga Res. 32: 372-383.

Perez-Alfocea F. 2015. Why should we investigate vegetable grafting? Acta Hortic. 1086: 21-29.

Poudel R, Jumpponen A, Kennelly MM, Rivard CL, Gomez-Montano L, Garrett KA. 2019. Rootstocks shape the rhizobiome: Rhizosphere and endosphere bacterial communities in the grafted tomato system. Appl. Environ. Microbiol 85: e01765-18. DOI: 10.1128/AEM.01765-18.

Quast C, Pruesse E, Yilmaz P, et al. 2012. The SILVA ribosomal RNA gene database project: improved data processing and web-based tools. Nucleic Acids Res 41: D590-D600.

Riley D, Barber SA. 1969. Bicarbonate Accumulation and pH Changes at the Soybean (Glycine max (L.) Merr.) Root-Soil Interface. Soil Sci Soc Am J 33: 905-908.

Rivard CL, O’Connell S, Peet M, Welker RM, Louws FJ. 2012. Grafting tomato to manage bacterial wilt caused by Ralstonia solanacearum in the southeastern United States. Plant Dis 96: 973-978.

Schell M.A. 2000. Control of virulence and pathogenicity genes of Ralstonia solanacearum by an elaborate sensory network. Ann R Phytopathol 38: 263-292.

Semangun H. 2006. Pengantar Ilmu Penyakit Tumbuhan [Introduction to Plant Pathology]. Gadjah Mada University Press, Yogyakarta. [Indonesian]

Solekha R, Susanto FA, Joko T, Nuringtyas TR, Purwestri YA. 2019. Phenylalanine Ammonia Lyase (PAL) Contributes to the Resistance of Black Rice against Xanthomonas oryzae pv. Oryzae. J Plant Pathol 102 (2): 359-365.
Sutrisno, Susanto F A, Wijayanti P, Retnoningrum MD, Nuringtyas TR, Joko T, Purwestri YA. 2018. Screening of resistant Indonesian black rice cultivars against bacterial leaf blight. Euphytica 214: 199.

Tian B, Xu Z, Sun Z, Lin J, Hua Y. 2007. Evaluation of the antioxidant effects of carotenoids from Deinococcus radiodurans through targeted mutagenesis, chemiluminescence, and DNA damage analyses. Biochim Biophys Acta 1770: 902-911.

Wang X, Wang Z, Jiang P, He Y, Mu Y, Lv X, Zhuang L. 2018. Bacterial diversity and community structure in the rhizosphere of four Ferula species. Sci Rep 8: 5345. DOI: 10.1038/s41598-018-22802-y.

Wei Z, Huang J, Yang T, Jousset A, Xu Y, Shen Q, Friman VP. 2017. Seasonal variation in the biocontrol efficiency of bacterial wilt is driven by temperature mediated changes in bacterial competitive interactions. J Appl Ecol54: 1440-1448.

Wei Z, Yang T, Friman VP, Xu Y, Shen Q, Jousset A. 2015. Trophic network architecture of root-associated bacterial communities determines pathogen invasion and plant health. Nat Commun 6: 8413 .

Widyaningsih S, Utami SNH, Joko T, Subandiyah S. 2019. Plant response and huanglongbing disease development against heat treatments on 'Siam Purworejo' (Citrus nobilis (Lour)) and 'Nambangan' (C. maxima (Burm.) Merr.) under field condition. Arch Phytopathol Plant Protect 52: 259-276.

Yanti Y, Fuji FA, Trimurti H, Chainur RN. 2017. Screening of rhizobacteria from rhizosphere of healthy chili to control bacterial wilt disease and to promote growth and yield of chili. Biodiversitas 18 (1): $1-9$.

Youssef NH, Farag IF, Rinke C, Hallam SJ, Woyke T, Elshahed MS. 2015. In Silico Analysis of the Metabolic Potential and Niche Specialization of Candidate Phylum "Latescibacteria" (WS3). PLoS ONE 10 (6): e0127499. DOI: 10.1371/journal.pone.0127499.. 